\title{
Sugarcane Field Merging Problem to Minimize Harvester's Logistics Cost
}

\author{
Nutthanan Issarapong ${ }^{\text {a, }}$, Sakda Khamjan ${ }^{\mathrm{b}}$, Supachai Pathumnakul ${ }^{\mathrm{a}}$ \\ ${ }^{a}$ Supply Chain and Logistics Systems Research Unit, Department of Industrial Engineering, Faculty of Engineering, \\ Khon Kaen University ,Khon Kaen 40002, Thailand \\ ${ }^{b}$ Faculty of Science and Engineer, Kasetsart University Chalermphrakiat Sakonnakhon Province Campus, \\ Sakhonnakhon 47000, Thailand
}

*Corresponding Author: nutthananice@ gmail.com

\begin{abstract}
Most sugar industries, in Thailand, are characterized by a large number of small independent growers. Small size field is not practical for using mechanical harvester to harvest cane in small area. In this paper, the problem of merging small sugarcane fields in order to gain the benefit of using harvester is studied. It is to select suitable sugarcane fields to be merged together and also to design the path direction of harvester in merged fields. An approach based on mathematical model is developed to solve the problem in order to minimize related logistics costs. The performance of the approach is investigated with some example cases. The results indicate that the model provides good solution and practical.
\end{abstract}

Keywords: bisection method, harvester; mathematical model, sugarcane.

\section{Introduction}

Sugarcane is an important economic crop in Thailand. It is planted around the country with approximately $1,477,480$ hectares plantation area and 103,665,750 tons of sugarcane yields per year. Most of sugarcane grown in Thailand is used as a raw material in sugar production ${ }^{(1,2)}$. Most sugar industries, in Thailand, are supplied by small independent growers that are scattering located over a large area surrounding the sugar mills. Most of the fields are quite small. It's sugarcane production is less than 300 tons per crop ${ }^{(3)}$. Traditionally, sugarcane is harvested by manpower, but due to the labor shortage and the continuously rising of labor wage, manually harvesting is increasingly difficult to manage for both growers and mills. Recently, the use of sugarcane harvester in harvesting operation has been increased ${ }^{(3)}$. Even though the mechanical harvesting is preferred, but there are two major implementing obstacles need to be managed. First, harvester is too expensive to be owned by most of growers. Second, the small size field is not practical for harvesting by harvester. If the length of field is too short, harvester will take several U-turns during harvesting operation. It causes non-value added harvesting time and damages sugarcanes at the edges of fields. However, in the studied of Adam E. Ahmed, it reported that harvesting by labor was costly than using harvester even taking into consideration the cost of sugarcane damaged by the harvesters when it takes U-turn in the field ${ }^{(4)}$. To manage these obstacles, expensive harvesters are owned by sugarcane mill and shared by many small-sized growers, and the nearby small-sized fields should be merged to gain benefit of using harvester to harvest.

In this paper, the problem of merging small sugarcane fields in order to gain the benefit of using harvester is studied. It is to select suitable sugarcane fields to be merged together and also to design the path direction of harvester in merged fields. The problem is addressed under the assumption that all fields provide the same sugar quality and have uniform production yield (ton/unit area). Figure 1 demonstrates the example of the small sugarcane fields and its path direction. The degree of path direction affects to the harvesting cost. An approach based on mathematical model is developed to solve the problem in order to minimize related logistics costs. 
The procedure developed to solve this problem consists of two main parts. The first part is to identify the suitable path directions of harvester for all field merging scenarios. The bisection method is applied to solve in this stage. In the second part, the mathematical model is used to optimally select the sugarcane fields to be merged. The objective function of the model is to minimize related logistics cost including harvesting cost and damaged sugarcane cost.

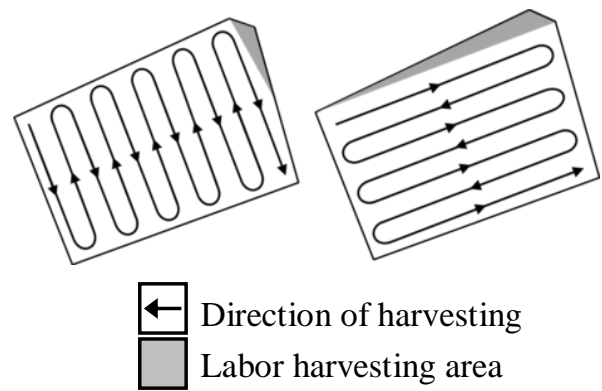

Fig. 1. The example of a sugarcane field with different harvester's path direction.

\section{Harvester path direction determination}

The bisection is the method used to find the range of answer $^{(5)}$. In this paper, the bisection method is applied to determine the suitable path direction of harvester for a set of merging sugarcane fields. Since the shape of sugarcane fields are not in geometric shape, the path direction of harvester in a set of merging fields affects to the harvester travelling distance. The proper path direction increases the travelling distance of harvester, then speeding up the harvesting process, reducing the quantity of sugarcane damaged by U-turn operations of the harvester, and lessoning the manually harvesting area. As shown in Fig. 2, the harvester needs to travel back and forth in harvesting area. The more U-turn operation, not only the more sugarcane is damaged, but the more harvesting time is wasted.

In fact, the growers harvest sugarcane by labor force in conjunction with the harvesters. Some small areas which are in irregular shape must be manually harvested since they are not possible to be accessed by harvester. The travelling distance per trip of the harvester should be long enough to achieve the benefit of harvester employment. In this study, we have estimate that the suitable travelling distance of harvester per one trip (i.e., continuously harvesting without U-turn operation) should not be less than 100 meters. Then, in merged field, the sugarcane will be harvested by labor force, instead of harvester, if the
A
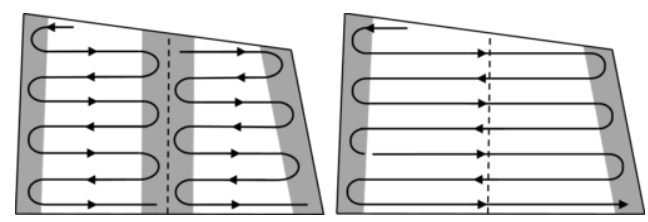

Direction of harvesting

Sugarcane damaged area

Edge of sugar field

Fig. 2. The comparison of damaged area when the harvester makes round trips.

cutting row is less than 100 meters.

To determine the proper harvester's path direction, the direction between 0 to 180 degrees is first considered. Then, the bisection method is employed iteratively until the best direction which is the direction providing the lowest logistics cost is found for each merging scenario. The logistic cost consists of labor cost, harvester cost and the cost of sugarcane damaged by harvester.

The parameters, equations and procedure of the bisection method used in this addressed problem are as shown.

$\alpha:$ Cost of harvesting by labor force (unit cost $/ \mathrm{m}^{2}$ )

$\beta:$ Cost of harvesting by harvester (unit cost $/ \mathrm{m}^{2}$ )

$\gamma$ : Sugarcane damaged cost (unit cost/harvester

U-turn operation)

$r_{j}$ : Area to be harvested by labor force in field merging pattern $j\left(\mathrm{~m}^{2}\right)$

$s_{j}$ : Area to be harvested by harvester in field merging

pattern $j\left(\mathrm{~m}^{2}\right)$

$t_{j}:$ Number of U-turn operations made by harvester in field merging pattern $j$ (time)

$C_{j}$ : Total cost occurred by employing field merging

pattern $j$ (Unit cost)

$j$ : Index of field merging patterns $(j=1,2, \ldots, J)$

$l$ : Lower degree of harvester's path direction allowed in a bisection method iteration 
$u$ : Upper degree of harvester's path direction allowed in a bisection method iteration

$g$ : Degree of harvester's path direction obtained by halving of the upper and lower degrees (i.e., $g=\frac{u-l}{2}$ )

Cost of harvesting by labor force and harvester for a field merging pattern $j$ could be calculated by (1) and (2), respectively. The equation (3) estimates the total cost of sugarcane damaged by using harvester in field merging pattern $j$. The total logistics cost considered in this study is as shown in equation (4).

$$
\begin{aligned}
& \alpha \times r_{j} \\
& \beta \times s_{j}
\end{aligned}
$$

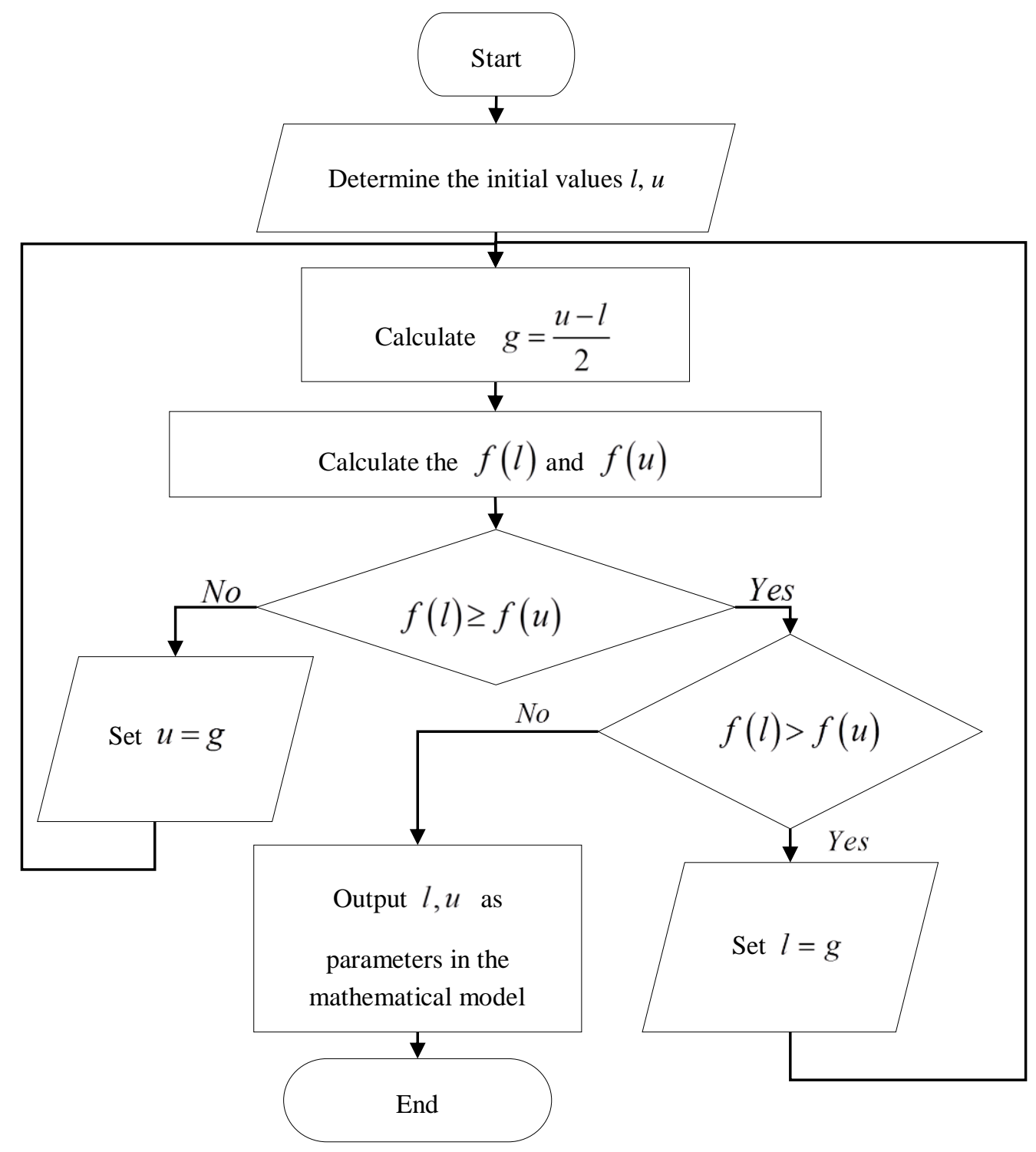

Fig. 3. The procedure to determine suitable harvester path direction based on bisection search method. 


\section{Mathematical model for selecting field merging pattern}

\section{Notations}

Sets and Indexes

$i$ : number of sugarcane fields

$j:$ number of field merging patterns

$I:$ index of fields, $i=1,2, \ldots, I$

$J$ : index of field merging patterns, $J=1,2, \ldots, J$

Parameters

$Q_{j}$ : sugarcane quantity could be harvested under field

merging pattern $j$ (tons)

Cap : maximum sugarcane quantity allowed for a field merging pattern (tons)

$Z_{i j}:$ the binary number used to indicate that fields $i$ is a member of field merging pattern $j$ (i.e., if field $i$ is in field merging pattern $j$, then $Z_{i j}=1$, otherwise, $Z_{i j}=0$.

Decision variables

$$
\begin{gathered}
X_{j} \in\{0,1\} \quad X_{j}=1, \text { if field merging pattern } j \text { is } \\
\text { selected, otherwise } \\
X_{j}=0
\end{gathered}
$$

The mathematical model is formulated as follows;

$$
\text { Minimize } Z=\sum_{j=1}^{J}\left(\mathrm{C}_{j} \times X_{j}\right)
$$

Subject to

$$
\begin{aligned}
& \sum_{j=1}^{J}\left(Q_{j} \times X_{j}\right) \leq \text { Cap } \\
& \sum_{i=1}^{I}\left(Z_{i j} \times X_{j}\right)=1 \quad ; \forall_{j} \\
& X_{j} \in\{0,1\} \quad ; \forall_{j}
\end{aligned}
$$

The objective function (6) is to minimize total logistics related cost in merging sugarcane fields. Constraint (7) ensures that the quantity of harvested sugarcane in each period must not exceed the sugar mill's capacity. Constraint (8) guarantees that each sugarcane field could be harvested only one time. Constraint (9) describes that the variables $X_{j}$ is binary.

\section{Algorithm Illustration}

To illustrate the employment of the proposed algorithm, the example of 10 sugarcane fields whose sizes are varied as shown in Fig. 4(a). The parameters such as unit area, unit cost, sugarcane yield are simulated following the genuine practice in sugarcane industry in Thailand. If there are not more than three fields allowed to be merged, then 59 field merging patterns are considered. The bisection search method is applied to determine the suitable harvester path direction in each field merging pattern. The most suitable path direction of harvester is the one that provides the lowest harvesting logistics cost. Results of some field merging patterns are as presented in Table 1. For example, in field merging pattern 33, fields 2,3 and 5 are merged. The harvester path direction is at 180 degree. It is estimated that 22,200 unit areas and yields 139 tons of sugarcane. Costs of harvesting by labor force (in the area that cannot be accessed by harvester), harvesting by harvester, and the sugarcane damaged cost (damaged sugarcane from the U-turn operation of harvester) are approximately 461, 2,876, and 980 unit costs. Then, the total cost is 4,316 unit costs, if fields 2, 3, and 5 are to be merged. The mathematical model, then, is used to design the combination of the field merging patterns than provide the lowest harvesting logistics cost and ensure that all fields are harvested. The solution of this

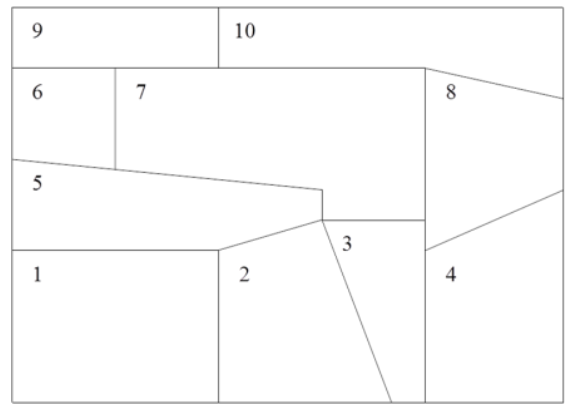

(a)

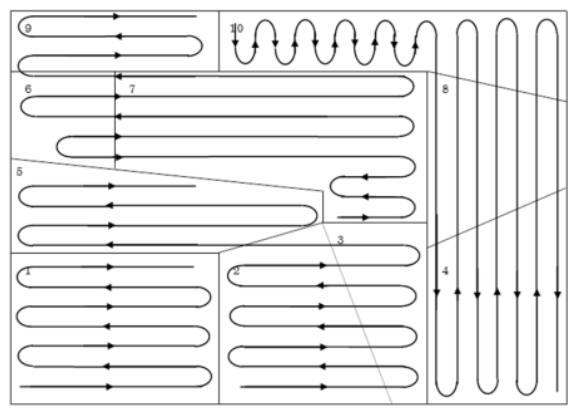

(b)

Fig. 4. An example of sugarcane field merging problem. 
Table 1. Results of some field merging patterns.

\begin{tabular}{|c|c|c|c|c|c|c|c|c|}
\hline \multirow{2}{*}{$\begin{array}{c}\text { Pattern } \\
(j)\end{array}$} & \multirow{2}{*}{$\begin{array}{c}\text { Merged } \\
\text { Fields }(i)\end{array}$} & \multirow{2}{*}{$\begin{array}{l}\text { Harvester } \\
\text { path } \\
\text { direction } \\
\text { (degree) }\end{array}$} & \multirow{2}{*}{$\begin{array}{c}\text { Total } \\
\text { harvesting } \\
\text { area } \\
\text { (unit area) }\end{array}$} & \multirow{2}{*}{$\begin{array}{l}\text { Sugarcane } \\
\text { yield (ton) }\end{array}$} & \multicolumn{2}{|c|}{$\begin{array}{l}\text { Harvesting cost } \\
\text { (unit cost) }\end{array}$} & \multirow{2}{*}{$\begin{array}{c}\text { Cane } \\
\text { damaged cost } \\
\text { (unit cost) }\end{array}$} & \multirow{2}{*}{$\begin{array}{c}\text { Total cost } \\
\text { (unit } \\
\text { cost) }\end{array}$} \\
\hline & & & & & Labor & Harvester & & \\
\hline 1 & $1,0,0$ & 180 & 12,000 & 75 & 0 & 1,608 & 660 & 2,268 \\
\hline 2 & $2,0,0$ & 96 & 9,000 & 56 & 1,125 & 1,016 & 450 & 2,591 \\
\hline 3 & $3,0,0$ & 96 & 4,800 & 30 & 1,097 & 446 & 180 & 1,722 \\
\hline 4 & $4,0,0$ & 90 & 9,600 & 60 & 0 & 1,267 & 520 & 1,787 \\
\hline$\vdots$ & $\vdots$ & $\vdots$ & $\vdots$ & $\vdots$ & $\vdots$ & $\vdots$ & $\vdots$ & $\vdots$ \\
\hline 30 & $1,5,6$ & 90 & 24,210 & 151 & 1,515 & 2,931 & 780 & 5,226 \\
\hline 31 & $1,5,7$ & 90 & 35,220 & 220 & 0 & 4,676 & 1,580 & 6,256 \\
\hline 32 & $2,3,4$ & 90 & 23,400 & 146 & 0 & 3,105 & 1,320 & 4,425 \\
\hline 33 & $2,3,5$ & 180 & 22,200 & 139 & 461 & 2,876 & 980 & 4,316 \\
\hline$\vdots$ & $\vdots$ & $\vdots$ & $\vdots$ & $\vdots$ & $\vdots$ & $\vdots$ & $\vdots$ & $\vdots$ \\
\hline 55 & $6,7,10$ & 180 & 42,600 & 266 & 1,571 & 3,370 & 770 & 5,711 \\
\hline 56 & $6,9,10$ & 0 & 41,610 & 260 & 3,523 & 1,696 & 260 & 5,479 \\
\hline 57 & $7,8,9$ & 180 & 47,430 & 296 & 375 & 3,476 & 910 & 4,761 \\
\hline 58 & $7,8,10$ & 0 & 53,850 & 337 & 263 & 4,024 & 920 & 5,207 \\
\hline
\end{tabular}

Table 2. Solution of the example case.

\begin{tabular}{|c|c|c|c|c|c|}
\hline $\begin{array}{c}\text { Selected } \\
\text { pattern }(j)\end{array}$ & Fields $(i)$ & $\begin{array}{c}\text { Cost } \\
\text { (unit cost) }\end{array}$ & $\begin{array}{c}\text { Total cost of merging } \\
\text { scenario (a) } \\
\text { (unit cost) }\end{array}$ & $\begin{array}{l}\text { Total cost of unmerging } \\
\text { scenario (b) } \\
\text { (unit cost) }\end{array}$ & $\begin{array}{l}\% \text { difference } \\
\text { of (a) \& (b) }\end{array}$ \\
\hline 1 & $1,0,0$ & 2268 & \multirow{4}{*}{18227} & \multirow{4}{*}{22724} & \multirow{4}{*}{$19.79 \%$} \\
\hline 33 & $2,3,5$ & 4316 & & & \\
\hline 47 & $4,8,10$ & 6876 & & & \\
\hline 54 & $6,7,9$ & 4767 & & & \\
\hline
\end{tabular}

example is as describe in Table 2 and Fig. 4(b). In the Table 2 , the cost of merged field solution is also compared to the cost when all fields are individually harvested without merging operation. It shows that merging field could lessen harvesting cost $19.79 \%$ compared to independently harvest.

\section{Results and discussion}

In this section, 4 problem cases were used to examine the performance and practicality of the proposed method. The problem cases consisted of 5, 10, 15 and 20 fields. In each case, 5 problems were randomly generated. The performances of the proposed algorithm were compared to the traditional unmerged field scenarios. The solutions from merging field procedure were approximately $12 \%$ better than unmerging scenario, on average. The cost saving results in 4 example cases are as shown in Table 3. It also found that percentage of cost saving depended on many parameters such as the shapes of fields and the difference between labor cost and harvester cost. If fields are in irregular shapes (i.e., not close to rectangle), fields were difficult to be merged and the harvesting by harvester is not much benefit compared to manually harvesting.

Table 3. Logistics cost saving by merging field approach.

\begin{tabular}{|c|c|c|}
\hline $\begin{array}{c}\text { Problem } \\
\text { case }\end{array}$ & $\begin{array}{c}\text { No. of } \\
\text { fields }\end{array}$ & $\begin{array}{c}\text { Cost saving by } \\
\text { merging fields }(\%)\end{array}$ \\
\hline 1 & 5 & 18.15 \\
\hline 2 & 10 & 5.29 \\
\hline 3 & 15 & 17.17 \\
\hline 4 & 20 & 7.18 \\
\hline
\end{tabular}

\section{Conclusions}

In this paper, the algorithm based on the bisection method and the mathematical model is developed and 
applied to sugarcane field merging problem. The solution of the model is to select suitable fields to be merged and also determine suitable path direction of harvester in each field merging scenario. The objective function of the model is to minimize total related logistics cost. The results indicated that the developed approach provides better and practical solutions compared to the traditional unmerging field scenario. It could relieve the shortage labor problem and reduce harvesting cost. Nevertheless, the small size and irregular shape fields deliver less benefit of field merging operation compared to large size and more rectangular shape fields.

\section{Acknowledgement}

Supply Chain and Logistics Systems Research Unit, Department of Industrial Engineering, Faculty of Engineering, Khon Kaen University ,Khon Kaen, Thailand.

\section{References}

(1) Noptada Chaibung, and Kanchana Sethanan : "Development of Decision-Making System for Allocating Cane Harvesting Laborers in Inbound Logistics of Sugar Cane and Sugar Industry", KKU Engineering Journal, Vol. 38, No. 3, pp. 275-284, 2011

(2) Office of the cane and sugar board (homepage on the Internet). The sugarcane production report year 2013/2014.

Available: http://www.ocsb.go.th/upload/journal/fileupload/ .9193-923pdf

(3) Pathumnakul S., Nakrachata-amon T., "The Applications of Operations Research in Harvest Planning: A Case Study of the Sugarcane Industry in Thailand", Japan Industrial Management Association Vol. 65, No.4E, pp. 328-333, 2014

(4) Adam E. Ahmed, and Amna O.M. Alam-Eldin : “An assessment of mechanical vs manual harvesting of the sugarcane in Sudan - The case of Sennar Sugar Factory", Journal of the Saudi Society of Agricultural Sciences, Vol. 14, Issue 2, pp. 160-166, 2015

(5) P. Mansouri, B. Asady, and N. Gupta., "The Bisection-Artificial Bee Colony algorithm to solve fixed point problems", Applied Soft Computing, Vol.26, pp.143-148, 2015 